\title{
Limites do reformismo bem intencionado
} STIGLITZ, Joseph E. Making Globalization to Work. New York: W.W. Norton, 2006. (Globalização: como dar certo. São Paulo: Cia das Letras, 2008)

SADI DAL ROSSO

\section{Resumo}

Em seu livro Making Globalization to Work, Joseph E. Stiglitz analisa a situação econômica contemporânea e aponta sérios problemas de concentração da riqueza mundial. Perante eles, assume postura de reformista radical. Tece ligações com o alter-mundismo, participando do encontro de Mumbai, Índia. Admira as decisões drásticas de países como a Argentina e a China. Almeja sobretudo construir seu nome, ligando-se à figura do grande John M. Keynes. Entretanto, suas propostas de reformas apresentam limites óbvios por não explicitarem quem serão os atores sociais que as conduzirão. Este e outros pontos críticos fazem com que não consiga perceber a grande crise financeira que estoura no centro do império capitalista mundial, por meio de uma especulação sem limites com crédito imobiliário, que afastou o mundo financeiro da base real da sociedade.

Palavras-chave: Globalização. Reformas. Atores sociais. Alter-mundismo. Crise econômica.

\footnotetext{
* Professor titular do Departamento de Sociologia da Universidade de Brasília (UnB).
} 
O processo de globalização produziu efeitos notáveis no campo do debate político, econômico, social e cultural. O livro "Making Globalization to Work" de Joseph E. Stiglitz é um desses fatos que suscitam a atenção do grande público por levantar um debate de peso sobre o mal estar da globalização no campo de atuação dos países desenvolvidos e subdesenvolvidos. Tomando uma ótica de esquerda, o leitor seria encaminhado a consultar o que os grandes autores da crítica escreveram, a exemplo de Noam Chomsky, Francisco de Oliveira e François Chesnais. Alguns temas são comuns a todos, como por exemplo, a questão ambiental, a crescente desigualdade de renda entre os assalariados, os desníveis entre países desenvolvidos e subdesenvolvidos, empregando terminologia cara aos movimentos e aos autores dos anos sessenta e setenta, e àquilo que genericamente se fala como a questão democrática ou o déficit democrático. Não é em razão das comunalidades que o livro merece ser visitado. Duas razões, a princípio, qualificam-no como recurso para temas da globalização. Antes de mais nada, o autor provém do mundo profissional da Economia, campo acadêmico e prático dominado pelo chamado pensamento único. Dominado, mas não exclusivamente. Neste aspecto, Stiglitz oferece contribuição significativa. Como economista e vencedor do Prêmio Nobel de Economia em 2000, tem condição de apresentar um quadro geral do sistema econômico da globalização e seus pilares: institucionais, tais como o Fundo Monetário Internacional (FMI) e o Banco Mundial (BM) e de agentes tais como as empresas transnacionais. Para montar este quadro sistêmico, certamente não foi de pouco valor o fato de carregar em seu "Curriculum Vitae" a condição de membro do ConseIho Econômico e Social do presidente Bill Clinton, bem como de principal economista do Banco Mundial. As condições ocupacionais, mais do que a formação profissional e a trajetória acadêmica são razões que sugerem que vale a pena ler "Making Globalization to Work". Em terminologia 
sociológica bourdieusiana, o autor carrega um formidável "capital intelectual" e, em terminologia mais genérica das Ciências Sociais, o autor tem acesso a 'inside information'. 'Inside information' não é atributo acessível no mercado das idéias a qualquer autor. 'Inside information' é um capital específico que se encontra ligado à 'posição de fala'. Todos os leitores estão em um determinado 'lugar de fala' que lhes permite acesso às informações gerais que circulam via Internet ou em livros escritos. Poucos autores, entretanto, têm o privilégio do acesso ao mundo interno do BM e do FMI, as duas grandes instituições do sistema pós-nacional, do sistema global. É em razão do 'inside information' acima de tudo, que o leitor não perde tempo em abrir o "Making Globalization to Work" e considerar os fatos lá escritos e as propostas feitas.

Os capítulos que tratam do desenvolvimento (2), do comércio (3), das patentes (4), da dívida (8) e do sistema das reservas internacionais (9) são os mais interessantes para o leitor brasileiro, não pelo fato de tratar do papel do Brasil no cenário internacional, que o autor simplesmente ignora, mas pelas idéias discutidas sobre economia e finanças internacionais. Avanço alguns elementos que apresentam Joseph E. Stiglitz para o leitor brasileiro. Todos os capítulos têm idêntica estrutura. São compostos de duas partes: na primeira, o autor oferece elementos descritivos, analíticos e teóricos; na segunda, apresenta um conjunto de propostas, considerando que seu objetivo maior é levantar proposições concretas em favor de uma globalização diferente daquela que está sendo implementada, nesse momento, pelas grandes atrizes do cenário internacional: as instituições supranacionais, as corporações multinacionais, os governos e os movimentos sociais. Esta é uma razão adicional para o leitor brasileiro consultar Joseph E. Stiglitz e avaliar suas idéias. O autor não permanece apenas no terreno da crítica. Apresenta e defende propostas de reformas. O perfil de Stiglitz é o de um reformador crítico. Já que o processo de globalização não funciona a contento para todos os agentes, o que poderia ser feito? 
Na qualidade de reformista, Stiglitz segue os passos de John Maynard Keynes. Quem ler o livro saberá que Keynes é a sua referência principal, citado nada menos do que seis vezes no texto. Mais do que discípulo, Stiglitz quer ser o Keynes do século XXI. Tal qual Keynes, Stiglitz afirma que as mudanças têm que ser feitas agora, no curto prazo, porque "no longo prazo, todos estaremos mortos", como escreveu Keynes. Tal qual Keynes, o autor propõe que o ímpeto terrorista do mercado tem que ser temperado pela ação dos governos e das instituições internacionais supranacionais. Todo o problema estaria em encontrar o correto equilíbrio - o autor escreve 'correct mix', dosagem correta - entre mercado e Estado. Isto indica em que terreno Joseph E. Stiglitz se posiciona. Ele não acompanha as idéias liberais, nem ultra-liberais, nem a cega visão do império do mercado, nem a tese do pensamento único. Joseph E. Stiglitz advoga um papel importante para o Estado no desenvolvimento nacional e na regulação do mercado internacional. Neste sentido, é um Keynes de nossos dias. Este, seu lado reformista.

A esta altura é necessário apresentar o ângulo crítico a partir do qual ele olha o sistema capitalista mundial. $\mathrm{O}$ autor se vale da posição de Conselheiro do Governo Clinton e de economista do Banco Mundial para olhar o mundo. Com a fantástica vantagem de 'insider', o autor deslancha críticas significativas ao NAFTA, à forma como o FMI conduziu a crise financeira de 1987 nos países asiáticos, às maneiras pelas quais os países desenvolvidos tentam impor seus pontos de vista nos tratados gerais do comércio e na Rodada de Doha, aos procedimentos do FMI em relação à crise argentina e assim por diante. A título de ilustração, umas poucas avaliações do autor permitem acessar sua verve crítica da globalização. Em relação ao NAFTA escreve que "passados mais de 10 anos, está claro que o NAFTA não teve sucesso" (p. 62) porque "aumentou a dependência do México em relação aos Estados Unidos" (p. 64), porque não conduziu o 
México a um crescimento robusto, porque contribuiu para aumentar sua pobreza (p. 64) em função da pressão das corporações (pp. 131 e 197) e por não ter gerado o número de empregos previstos naquele país (p. 64).

O leitor deve estar esperando por saber se o autor escreve alguma coisa sobre o Brasil. Pouco, mas escreve. E o que escreve não é nada favorável. Questiona se não teria sido melhor para o Brasil ter enfrentado a bancarrota, como fez a Argentina, do que seguir a política conservadora do Banco Central de Henrique Meireles e seus associados (p. 224), de pagar a dívida externa e de fazer imensa reserva internacional. Não descreve, em nenhum momento, que o Brasil esteja desempenhando qualquer papel no cenário internacional, como, por exemplo, no Grupo dos 20 ou em discussão na rodada de Doha. Em outras palavras, a política de desenvolvimento seguida pelo Brasil em nada agrada o autor que propugna por outras alternativas. Exemplos bem sucedidos são a gestão argentina da crise econômica com a negociação da dívida e dos títulos; o crescimento sustentado durante três décadas da China após a Revolução Cultural; as políticas alternativas tomadas pelos países asiáticos após a crise mortal de especulação que os afetou entre 1987-8, e as políticas bem sucedidas com uma forte participação do Estado, regulamentando o mercado, como na Suécia. Nada na política brasileira atrai o autor. Atraem-no as mudanças drásticas como a Revolução chinesa e a bancarrota planejada argentina, que desembocaram em firmes processos de crescimento. Já Cuba não está na mesma posição e é simplesmente ignorada no livro.

A esta altura, já é tempo de parar e analisar aquilo que o autor escreve, avaliar e realizar uma crítica da crítica.

De que lado está Joseph E. Stiglitz? Quem o sustenta? O autor opera no campo das ideias, mas também das propostas práticas. Sem sombra de dúvida, poder-se-ia dizer que o campo político de Joseph E. Stiglitz é representado pela democracia norte-americana, na figura do Partido Democrata, e seus apoios acadêmicos provêm dos economistas críticos da forma atual que o processo de globalização tomou, bem como dos 
economistas críticos do pensamento único e da ideologia liberal da plena ação dos mercados. Stiglitz busca primeiramente apoio do pensamento centrista em termos de construção política, mas com um rabo de olho voltado para a esquerda. $\mathrm{O}$ autor acena para a esquerda, representada pelo pensamento altermundista, cuja bandeira de "um outro mundo é possível" - o capítulo primeiro é intitulado "um outro mundo é possível" de forma claramente convocatória. O fato de ter participado da edição do Fórum Social Mundial em Mumbai, Índia, indica até que ponto o autor tenta atrair apoios e leitores com perfil político de esquerda. Por outro lado, não busca apoio nem faz entrada junto à esquerda, mais à esquerda do alinhamento político. Em seu livro, jamais faz uma referência a Chomsky e a outros autores de esquerda mais radical. O autor estende seu apelo e busca apoios políticos na direita, junto às corporações, cujo papel defende, ainda que faça críticas ao poder excessivo que detém, ao sistema de monopólio que impõem e ao sistema de corrupção frequentemente utilizado como meio de ação para obter suas almejadas metas maiores. Stiglitz busca apoio também no campo da direita e do grande capital, o que conforma um poderoso leque de forças, tanto a CentroEsquerda, como a Centro-Direita.

O raciocínio conduz à seguinte questão: Poderão suas propostas reformistas tornar-se realidade na prática nacional e internacional? Que outro processo de globalização seria criado se suas propostas fossem integralmente implementadas? Ao processo de globalização "conforme está sendo conduzido" pelas grandes potências e pelas corporações, o autor opõe a reforma do sistema: "um outro mundo é possível", "um outro processo de globalização capitalista mais justo é possível". Muitas das propostas quanto ao papel, estrutura e composição dos organismos supranacionais, quanto à forma como os tratados internacionais são redigidos e implementados ante a pressão das grandes corporações internacionais, quanto ao lugar do comércio internacional, quanto ao combate à fome, quanto aos direitos de marcas, patentes e de propriedade intelectual, se 
implementados, teriam um impacto formidável sobre o desenvolvimento internacional. A questão central, entretanto, reside no seguinte: as ideias se materializam se encontram atores que as conduzem à prática. Neste respeito, encontra-se o principal ponto fraco do autor. Quem será o agente social que fará a transformação? Ainda que flerte com a esquerda, com os movimentos sociais alter-mundistas, o autor não se dá conta do potencial que o mundo dos trabalhadores pode ter. Opera no sentido de arregimentar apoios entre governos, capitães de empresas e uma difusa massa de 'movimentos sociais'.

Muitos cientistas sociais escreveram sobre a importância da vitória no debate intelectual como pré-condição para a materialização das idéias. Outros autores mais realistas voltaram seus discursos para uma classe, um grupo social concreto que, após conquistados pelas ideias, realizam a transformação.

O dilema sobre o qual se equilibram as propostas de Joseph E. Stiglitz, este, entre o idealismo das idéias e os interesses concretos materializados nas corporações, nos governos dos Estados, no modo de vida dos países mais ricos. Conquanto não se possa dizer que as idéias não possam, por impulso do seu fôlego, tomar lugar a despeito da estrutura, também não se deve esquecer do poder constringente da estrutura sobre o reino das idéias. Tal como escreveu Noam Chomsky no livro 'Failed States' (2006, p. 262): “Os Estados Unidos da América buscam os interesses estratégicos e econômicos dos setores dominantes da população, enquanto a retórica floresce sobre sua dedicação aos valores mais elevados. Este é praticamente um fenômeno histórico universal". O que tende a ser assim, especialmente no caso das idéias que padecem de não ter um ator social que as carreguem e implementem.

Para o leitor de hoje, a maior fragilidade do bem intencionado reformismo de J. E. Stiglitz reside no fato de que lhe passou completamente em brancas nuvens a grande crise financeira que se abateu sobre o mundo em setembro de 2008 e cujo impacto sobre crescimento econômico, pos- 
tos de trabalho e renda, prevê-se que sejam devastadores. Se as reformas propaladas pelo autor não atingem o olho do vulcão, de onde procede a lava que ameaça o mundo, que reformas vale a pena discutir?

\title{
Limitations of the well-intentioned reformism
}

\begin{abstract}
In his book, Making Globalization Work, Joseph E. Stiglitz examines the contemporary economic situation and identifies serious problems related to global wealth concentration. In face of these problems, he plays the part of the radical reformist. He dialogues with the alter-globalization movement, as a participant in the meeting of Mumbai, India. He admires the drastic decisions of countries such as Argentina and China. His aim is to promote his own name, through an association with the great John M. Keynes. However, his proposals for reform do not have clearly defined limits, since they do not reveal who are the social actors that will lead them. This, together with other critical points, make it difficult to perceive the great financial crisis that has erupted at the center of the global capitalist empire, as a result of a boundless real estate speculation that has disconnected the financial world from the real basis of society.
\end{abstract}

Keywords: Globalization. Reform. Social actors. Alter-globalization. Economic crisis.

\section{Referências}

STIGLITZ, Joseph E. Making Globalization to Work. New York: W.W. Norton, 2006. (Globalização: como dar certo. São Paulo: Cia das Letras, 2008)

Recebido: 17/12/2008

Aceite final: 11/03/2009 